\title{
Unsuccessful Transitions: Understanding Dropout from the Athletes' Perspective
}

\author{
By Georgios Andronikos ${ }^{*}$, Tony Westbury ${ }^{\dagger} \&$ Russell J.J. Martindale
}

Limited studies have investigated the experiences of athletes who did not 'make it' to elite level. To target this research gap, this study accessed and investigated this hard to reach population in order to understand the development and transition experiences of athletes who did not manage to negotiate successfully the junior to senior elite transition. A qualitative methodology was utilised and six athletes were interviewed. Inductive analysis showed that an unsuccessful transition from junior to senior level is highly individual and is attributed to a combination, rather than a single factor. The factors emerging from the work, which can increase the risk of athletes dropping out included: poor communication; inappropriate support; balancing a dual career without support or with excessive pressure; and a win focus environment during the development stage. Implications for coaches and policy makers with regards to impacting positively on both the transition experience itself and earlier foundation experiences are discussed further.

Keywords: Dropout, Elite Sport, Talent Development, Transition from Junior to Senior Level.

\section{Introduction}

Talent development has been shown to be complex, with the pathway towards elite level consist of multiple stages and transitions (Bloom 1985, Stambulova 1994). Successfully dealing with those transitions is of critical importance to becoming a professional athlete. The most commonly used theoretical models of 'within career' transitions are those outlined by Stambulova (2003) and Wylleman and Lavallee (2004). These models highlight the complexity of the trajectory to elite level. More specifically, in each transition, athletes are likely to face multiple demands and barriers that they need to cope with by drawing upon the necessary personal and external resources (Stambulova 2003). In addition, Wylleman and Lavallee (2004) identified a range of normative transitions that athletes may face across a number of categories including athletic, individual, psychosocial and academic/vocational. Importantly, different types of transitions may occur at the same time, something that is particularly likely around the junior to senior transition, which adds to the complexity of the challenge to be overcome. On top of this, unexpected, or non-normative transitions, increases the level of challenge that athletes have to cope with further still.

\footnotetext{
*Teaching Associate, Edinburgh Napier University, UK. ${ }^{\dagger}$ Associate Professor, Edinburgh Napier University, UK.

*Associate Professor, Edinburgh Napier University, UK.
} 
According to Stambulova et al. (2009), the transition from junior to senior level is a normative transition defined as taking place when an athlete starts to participate in adult competitions. This transition represents the entrance to the mastery stage and is hypothesised to last between one and four years. This transition is commonly said to be the most demanding and difficult in the trajectory towards elite level in sport (Stambulova et al. 2009). As a consequence, many talented athletes stall, move to recreational sport or even dropout during the transition from junior to senior level in sport (Stambulova et al. 2009).

Research in the area of dropout however, has focused mainly on children and adolescents, finding that dropout is associated with lack of enjoyment, perceptions of competence, social pressures, competing priorities and physical factors (Crane and Temple 2015). While these factors may be relevant to the transition to elite senior status, it is difficult to generalize due to the very different nature of the elite transition as compared to performance or recreational sport. While much of the sport career transition research has previously focused on retirement, more researchers are now focusing on the relationship between dropout and quality of within career transitions (Parket al. 2013). More specifically, in the systematic review from Park et al. (2013) an association between dropout and quality of career transitions was found highlighting that athletes who dropout may experience identity problems, negative emotions (Alfermann 1995, Koukouris 2001), loss of social networks and feelings of rejection (Butt and Molnar 2009).

It is clear that more research is warranted specifically addressing dropout between junior and senior elite level, however it is important to highlight that a small number of studies have investigated this issue in UK (Gledhill and Harwood 2015, Holt and Mitchell 2006), Canada (Fraser-Thomas et al. 2008, Wall and Côté 2007) and German sport (Baron-Thiene and Alfermann 2015). Fraser-Thomas et al. (2008) compared the experiences of successful and dropout swimmers and identified that dropouts had early success, limited access to individualised coaching, pressure from the parents and lack of healthy competition. Moreover, Wall and Côté (2007) compared the development experiences of high-level players who dropped out to active youth hockey players. They showed that players who dropped out started off-ice specialised training significantly earlier than the active players did (mean age of 11.75 years versus mean age of 13.8 years) and invested significantly more time in specialised training than active players at young ages (12-13).

Gledhill and Harwood (2015) examined the experiences of talented footballers who did not manage to reach elite senior level and findings revealed that a multitude of factors may contribute to an unsuccessful transition such as external pressure from their social circle, role conflict (player vs adolescent female) and lack of development opportunities. Based on those findings the authors made the following recommendations: athletic career in sport and education need to co-exist; dual careers should be supported; social agents need to be educated on how to support athletes throughout crucial transitions; coaches need to develop players holistically. Furthermore, personal characteristics such as motivation, determination, planning, coping strategies and tangible support can differentiate successful from those who did not manage to pursue a career at elite 
level (Baron-Thiene and Alfermann 2015, Holt and Mitchell 2006). In line with this, Stambulova (2017) suggested that more attention should be given to negative transition experiences and the relevant environmental/contextual factors, to enable an increased understanding of the transition from junior to senior level and consequently facilitate an effective evidenced based development of athletes.

However, it is important to recognise the potential impact previous experience may have on a transition. For example, Butcher et al. (2002) recognised the potential impact of the previous developmental experiences on career progression and dropout, suggesting that participation in deliberate play activities and sampling need to be to be part of the development programme prior to emphasizing on deliberate practice. The reason for this is that sampling (participate in multiple sports) fosters enjoyment, lifelong participation (Kirk 2005) and promotes the development of intrinsic motivation (Côté et al. 2009). On the contrary, numerous negative outcomes have been linked with early specialization such as injuries, anxiety and burnout (Hecimovich 2004). In addition to the development experiences, the motivational climate created by the coaches can affect athletes' motivation. For instance, environments that are autonomy supportive and task oriented can promote self-determination (Amorose and Anderson-Butcher 2007), through the satisfaction of basic needs competence, autonomy, and relatedness (Deci and Ryan 2000). On the contrary, controlling and ego-oriented environments are related to extrinsic motivation (Meyer et al. 2004). It has also been suggested that dropout is linked with low level of self-determination (Balish et al. 2014). As such, the nature of the motivational climate is vital as it affects the type of motivation of athletes, which has a strong link with career progression in the athletic career.

In summary, research has shown that development experiences, barriers and the environmental factors can influence the outcome of the trajectory to elite level. Culture itself has an effect on athletes' transitions (Ryba et al2013) and therefore the development of athletes in different cultures and environments needs to be explored (Henriksen et al. 2014). However, only a few talent development studies have examined negative experiences of talented athletes who did not manage to have a successful transition from junior to senior level. Some of this research has been conducted in Greece in relation to dropout from elite sport (Koukouris 1991, 2001, 2005). In recent years there have been no studies examining this area which limits our knowledge and understanding of the transition process from junior to senior level and of the potential impact of austerity measures on sport (Giannoulakis et al. 2017) and as a consequence on the development of athletes. As such, investigating the perspective of athletes who dropped out during that challenging phase of their career (transition from junior to senior level) will extend our understanding regarding the reasons that may lead to dropout and the potential link of development experiences with dropout. The aims of this study were a) to investigate the development and transition experiences of talented athletes who had an unsuccessful transition from junior to senior level and b) to identify environmental and individual factors that contribute to unsuccessful transitions. 


\section{Methodology}

\section{Participants}

Six participants from Greece ( 3 males and 3 females) that had competed at national level as junior athletes and dropped out from competitive sport during the transition from junior to senior level in sport were included in the study. There was one basketball player aged 27 (participant 1), one swimmer aged 24 (participant 2), one fin swimmer aged 23 (participant 3), one synchronised swimmer aged 26 (participant 4), one track and field athlete (sprinting) aged 25 (participant 5) and one football player aged 27 (participant 6). Four of the six participants had started competing at elite senior level in their respective sport. However, the athletes who participated in this study did not manage to maintain at elite level and dropped out within the first 18 months of their transition to senior level. Two of the six participants dropped out at the beginning of the transition process from junior to senior level. Achievements of the participants include world record at senior level, gold medals in European competition, silver and bronze medals in international competitions and gold medals in national competitions.

\section{$\underline{\text { Design }}$}

To understand the development and transition experiences of the participants, the researchers adopted thematic analysis (Braun and Clarke 2006) following a retrospective approach, which allowed participants to reflect on previous life events (Creswell 1984). Thematic analysis is characterised by (genuine) theoretical independence and flexibility, and organic processes of coding and theme development (e.g., Braun and Clarke 2006). To understand the pathway of talented athletes and the reasons that lead them to drop out a constructionist ontology with a focus on the interpretation of participants' words and opinions to construct a theory was followed (Terry et al. 2017). A qualitative approach was deemed to be the most appropriate for the aim of the current study since it allows the researcher to examine more in depth areas linked with the research objective by utilizing probes (Guest et al. 2013) for clarification and further discussion of a specific point (Patton 2002). To maximize the chances of gaining a complete picture of the nature of the transition to elite senior level, a semi-structured interview was developed based on the theoretical models of Côté et al. (2007), Stambulova (2003) and Wylleman and Lavalee (2004). For example, 'could you describe your career within sport until you dropped out?', 'which were the pivotal points and main challenges throughout your career?' and 'from your personal experience, could you describe why you did not reach your full potential?'. The researcher conducted two pilot interviews with athletes who had dropped out from sports, which helped to the evaluation and refinement of the interview guide in order to improve the flow and the wording of some questions to generate open-ended responses (Patton 1990).

This approach was chosen in order to allow flexibility when exploring areas that may emerge during discussions with the participants (Rynne et al. 2010). The 
interviews were conducted in Greek language since it was the native language of the researcher and the participants. Therefore, this enabled them to share their experiences and feelings and eliminated any language barriers during the interview. To ensure the in-depth examination of the development and transition experiences each athlete was asked the same sequence of questions, although further clarification and probing was used as required (Patton 1990).

\section{Procedure}

The study gained ethical approval from the Research Ethics and Governance Committee. Participants who fulfilled the selection criteria were recruited via a snowball sampling technique (Piereson 1983). According to Hardon et al. (2004), purposeful snowball samples allow researchers to easily find and be introduced to knowledgeable people who fulfil the inclusion criteria of the study and are able to answer informatively the research questions. Considering the unique nature of the participants and the difficulty in recruiting those individuals the snowball technique was of paramount important for the success of the study. All the participants were informed that it is not obligatory to participate in the study and they would be able to withdraw at any moment. Consent was gained from participants prior to their interview. They also were informed that if they agree to take part in the study all the data would be anonymised and confidential as much as possible.

Prior to the agreed date of the interview the main interview questions were sent to the participants in order to allow them to familiarise themselves with the type of the questions of the interview (Martindale et al. 2007). The rationale behind this decision was based on the literature suggesting that when participants have more time to consider their responses the data they will provide will be richer and denser (Burke and Miller 2001). Four of the interviews were conducted faceto-face and two were conducted via Skype because this was the most suitable for the participants at that time. The interviews were conducted by the lead researcher lasted approximately 64 minutes and were recorded, transcribed verbatim in Greek and then translated in English. Guidelines suggested by Patton (1990) were also followed in order to guide the interviewer away from biasing the responses of the participants. This was facilitated by the use of neutral and impartial position when probing participant responses, combined with the build of rapport, comfort and open responses (Backstrom and Hursch-Ceasar 1981).

\section{Data Analysis}

Inductive thematic analysis was used to analyse the data collected from the interviews (Edwards et al. 2002). Adopting an inductive approach means that the themes that were identified were strongly linked to the data themselves (Patton 1990). The researcher followed the following phases during the thematic analysis: familiarization with the data by reading and re-reading the data and taking notes of 
initial ideas, generating initial codes, searching for themes, reviewing themes, defining and naming themes and finally producing the report. (Patton 1990)

Moreover, the researcher used member reflections to explore any gaps in the results or similarities regarding the interpretations of the findings (Schinke et al. 2013). Following the recommendation from Shenton (2004), frequent debriefing sessions between the researchers were organised in order to reduce the potential bias of the researcher and reflect on the analysis process by discussing points that were either over or under emphasised and remove any assumptions. In addition, seeking agreement from an expert in the field and using representative quotations were techniques used to increase the credibility of the current study (Graneheim and Lundman 2004). Finally, reflective commentary was used in order to allow the research to reflect and evaluate the process of the data analysis (Lincoln and Guba 1989).

\section{Results and Discussion}

The main themes and subthemes that emerged from the data through inductive analysis form the structure of the results and discussion section, with description and representative quotes to exemplify and provide evidence for each theme presented. Findings are also linked and discussed in relation to the relevant literature. The main themes (factors contributing to an unsuccessful transition) that emerged were: 1) early success and win focus environment, 2) negative impact of coaches and different stakeholders, 3) lack of communication and support towards athlete wellbeing, and 4) challenges of combining sport with studies.

\section{Early Success and Win Focus Environment}

Early success during the development stage was a common theme amongst all the athletes of this study. Interestingly, research has shown that there is a low correlation between performances at young ages and later success at elite senior level (e.g. Barreiros et al. 2014, Brouwers et al. 2012). More specifically, participants reported that when they were young they found it easy to win the majority of the competitions they participated. This boosted their confidence and acted as a trigger for them to believe in themselves and become more interested in their sport. However, it appears that not facing defeats did not help them to develop the necessary skills for dealing with transitions and achieving excellence in sport (Collins and MacNamara 2012, MacNamara et al. 2010a, 2010b). A recent systematic review showed that psychological characteristics of selfregulation, resilience, commitment and discipline can facilitate the effective development and can differentiate elite from non-elite athletes (Gledhill et al. 2017). 
II was winning gold medals all the time, apart from a few races that I won silver medals. I was competing in regional competitions until I started high school and I was training a lot every day. During high school, I was first in my region and I was qualified for the national competition. I went and I did very well.'

Participant 5

I believe that things get more serious around the age of 13-14 when you start competing in the national leagues. When I was 15 I won my first medal and you know... you think Wow! I am good at this and you get more interested...'

Participant 2

This early success gave the opportunity to some of the participants to become members of the regional/national youth teams. Consequently, a number of youth athletes received increased attention and gained access to better quality coaching mainly because of their successful performance at the development stages of their youth career. This process therefore can potentially create unequal opportunities amongst athletes, which may influence the development of individuals that had not managed to demonstrate their talent at that stage. The fact that talent takes time to emerge is evident in the literature (Simonton 1999) and many researchers have highlighted the need for equal opportunities during the development stages of the athletic career (e.g. Andronikos et al. 2016, Brazo-Sayavera et al. 2017).

'When I was 16 I won a gold medal in the national league, became a member of the national youth team and participated in international competitions. I finished second in the final of the European league.'

Participant 2

'When I was 12 and a half I joined the national youth team so you can imagine how fast 5 times per week became 6-7 times per week. This meant that I was training many hours per week. I remember I had to leave school early sometimes to go to the training and to competitions. When I started the high school the level and the intensity were higher so I felt that the sport was much more competitive from that point onwards.'

Participant 4

Furthermore, the win focus environments reported had a negative impact on the motivation of athletes to remain engaged in their sport. Participants reported that they did not learn to love the sport and enjoy themselves when they started competing during their development stage. 'Loving the sport' can be linked with the concept of intrinsic motivation (Deci and Ryan 2008), which is associated with reduced chances of drop out (Burgess and Naughton 2010). Data showed that the win focus environment of the teams and the craving of coaches to win as many games/competitions as possible at youth level have an impact on the development of athletes. Participants also described that short-term goals might include the 'sacrifice' of athletes by forcing them to compete in different categories because of their outstanding performances at that time. It is well established in the literature however, that talent development environments focusing on long-term coherent goals, while emphasizing appropriate development rather than early success, 
coupled with athlete understanding and communication facilitate effective development of talented athletes (Martindale et al. 2007).

'The truth is that we didn't learn to love the sport, we learned to win and to play for the win because that was the mentality of the team since we were the best of our region. Therefore, the youth teams were structured with a winning focus but there was no enjoyment of the game.'

Participant 1

'The sacrifice to win a medal or achieve a specific target set by the coach can drain you mentally and physically. Trying to achieve that goal may lead you to burn out. If the coach registers you in three different categories the body melts, you get exhausted and this is a reason for a talented athlete not only to stop developing but even drop out from sport.'

Participant 4

Unhealthy competition within the environment of the team was another element that was highlighted by the athletes, and has been reported previously (Fraser-Thomas et al. 2008). Teammates were competing against each other rather than working hard together in order to get better as part of a healthy competition environment that fosters peer-to-peer learning and development. The nature of the environment is of particular importance as well because players in team sports such as football are expected to move from a caring and nurturing environment to a brutal and outcome-oriented environment at the senior level (Richardson et al. 2012). This reality coupled with the lack of exposure to elite senior environments (as junior athletes) may cause difficulties to their adjustment at this level (Bruner et al. 2008). Therefore, gradually introducing players to the senior squad and educating them regarding the difficulties of the transition would help them build internal resources to manage demands and seek support from others (Morris et al. 2015, 2016).

'We were very competitive against each other, we were thinking who will manage to 'eat' each other and be the best within a duet. We hated each other we only cared who would perform better individually.'

Participant 4

\section{Negative Impact of Coaches and Different Stakeholders}

Participants reported that there were many conflicting goals and agendas from their coaches, agents, board members and federations during their development. All three team sport athletes emphasised a significant role of agents because they believed that networking can determine which youth athlete will step up to higher levels of competition. Being part of a regional/national youth team, or knowing a coach who has a good network or having an agent that will promote the player, it is possible to create more opportunities for athletes. 
'If you don't have a good agent or if you don't play for the regional/national youth team you won't progress. You will reach at a certain level and then you need to find an agent and pay him in order to progress. Essentially, you need an agent to progress; no matter who you are or how good you are if you find a good agent he will help you progress.

Participant 6

'Despite she was the world champion she didn't participate in the Olympic Games but the athlete who won the European championship did because her father had connections in the federation. We are too 'small' to understand, it is something like politics, we are too 'small' to understand... This sport is very controversial, basically, all the sport that include judges.'

Participant 4

One of the participants provided an example of a not so talented individual who had access to good quality coaching because of the sporting background of their family, which allowed him to significantly improve. As such, there are cases that even athletes who did not achieve exceptional performances as youth athletes but through other pathways had increased opportunities enabling them to progress at a higher pace compared to the rest. Those varied opportunities could be linked with luck or chance, which has been highlighted in the literature as another factor that may influence development (Gagne 2004). This example highlights the fact that the talent pool should be as large as possible at earlier stages of development because athletes develop at different rates (e.g., Martindale et al. 2007).

'There was a player Trifonas and when we were young he was moving away to avoid getting hit by the ball. Trifonas made individual training every summer with a particular coach, the Nureyev [expert] of Greek Basketball Petros; great player and a great coach. Trifonas had a great network and he was also coming from a sport family. His father was a referee, his uncle was the coach of the regional youth team and in general, Trifonas was supported. Eventually, he came back after summer training and he could dunk.'

Participant 1

Athletes emphasised on the fact that some of the people who take decisions have personal agendas or promote their network or even lack knowledge in regards to the sport. Examples were reported where these influential people are mainly interested in public relations without having the skills or expertise nor the willingness to facilitate equal opportunities and effective development. For instance, board members that have limited or no experience/knowledge of a sport may take vital decisions regarding the structure of a team or the selection of athletes. Several cases of corruptions have been reported related either to competition results whereby the involved parties can be the officials and/or the athletes or non-competition focused decisions usually referred as 'management corruption' (Maennig 2005). 
'Many people that are in involved in sport as board members have never participated in sport in their lives. They are there only for the public relationships. Nonetheless, these people take the decisions and influence the development of athletes. They are a variable that influences the development of athletes.'

Participant 2

'Board members play a huge role because most of the times these are the people who because of bribing or relationships or other reasons may put aside a talented athlete to achieve their personal goals or help another athlete because is part of their network...'

Participant 4

\section{Lack of Communication and Support towards Athlete Wellbeing}

Athletes described that in some cases coaches did not respect their athletes and their personal aspirations. Not supporting the life choice of an athlete can be a barrier for their development that may even lead to dropout from sport. According to the interviews, athletes often sought discussion and communication with coaches, because they valued their opinion. However, athletes reported often having to simply follow commands from their coaches without understanding clearly the coaches' expectations or discussing their long-term plan with them. This description is in contrast to theories such as, transformational leadership theory, which suggests that leaders build relationships based on personal, emotional and inspirational exchanges with the goal of developing followers in their fullest potential (Bass et al. 2003). This is of particular importance as transformational leadership has been linked with lower levels of burnout (Hetland et al. 2007), reduced stress (Bono et al. 2007) and increased well-being (Nielsen and Munir 2009, Nielsen et al. 2008).

If felt that there was no communication between us. There was no discussion between me and my coach about what I wanted or about what he thought it was the best for my development.'

Participant 5

'He didn't respect that she had a life outside from sport. He acted against her will despite she told him that she wanted to go to the exams at these specific dates because it was important for her.'

Participant 2

In addition, bad behaviour from coaches towards athletes by offending them verbally was reported as another aspect of negative behaviours from coaches that may take place. Those negative behaviours couples with excessive pressure regarding weight management for example that is a critical aspect of some sports like synchronised swimming may affect wellbeing by even leading to eating disorders as described by the synchronised swimmer. 
'We had a coach who had a very bad behaviour towards us. For instance, if you gained a kilogram he would humiliate you in front of the whole team and usually in front of other important persons. This pressure regarding our weight led some of the girls to intentionally throw up and they were coming to training with broken vessels. It is a very violent sport for the soul of a kid. Around the age of 17, I had an eating disorder likewise the most of the girls that were in the team.'

Participant 4

Moreover, an outcome-oriented environment inevitably seeks winning and money. Thus, athletes felt that their needs were neglected and the top priority was either money or winning or both without genuine interest in the athlete. This lack of interest regarding the athletes made them less satisfied with their sport and was reported to contribute to their unsuccessful transition. This point is supported by research examining successful environments, where it is highlighted that factors such as athlete welfare, communication, and achievement-orientation are necessary for an optimal talent development environment (Henriksen et al. 2010a, 2010b, Mills et al. 2014).

'They were cold-hearted and they were only interested in performance. They expected from you to win points according to the money you were getting paid. I didn't like this because I felt there was no honest interest for the athletes. I felt that the people around me coaches, athletes, board members had a completely different philosophy and I couldn't communicate with them so I thought that I didn't want to continue anymore, I fed up with this situation and I decided to stop swimming gradually.'

Participant 2

On one occasion, a coach recommended to his athlete to take anabolic steroids to increase performance in order to be successful, suggesting that this is the only way to progress. Additionally, participant 6 stated that they believed the high demands and expectations of sport push athletes to use anabolic steroids or become victims of (over) advertising, which as a consequence their wellbeing may be affected.

'I had a coach that was saying for me: "she is only competing fairly; how does she expect to be successful like this?" I have heard him saying that. He meant that I didn't agree to take anabolic drugs. The coach did not believe in me and expected from me to take illegal performance enhancing drugs. A coach that consents to give drugs to his athletes is tragic and not respectable at all. How can you trust with this behaviour and how can you let them guide you? Of course not.'

Participant 2

'Sport have lost their meaning and have the crossed the line towards "super sport". "Super sport" lead people to death by the use of anabolic steroids. Over advertising is another issue, even the biggest clubs and the greatest players are driven by companies, sponsors and money.'

Participant 6 
It was reported that the attitudes of parents could also potentially impact the performance of athletes and eventually their development as well. Athletes described that parents projecting their negative feelings (e.g. parents arguing between them) to the children especially during a stressful time (e.g. a competition) can influence negatively on their concentration, may cause distress and affect the quality of their performance. Research has shown that family plays a significant role in shaping youth sport experiences both from a positive (athlete motivation levels, elite sport participation) and negative (drop-out) perspective (Sheridan et al. 2014). Similar behaviours identified in the literature are the following: being negative and critical, focusing on winning, being controlling and over pushing (Lauer et al. 2010).

'My parents had an argument that day and generally, my dad was pressuring me at that time very much with the things he said to me and my psychology was really bad. My dad told me that they will break up with my mom just before the big national competition and it influenced me very much.'

Participant 5

Additionally, inappropriate support, which may have two different forms: either not offering enough support or creating unnecessary pressure towards the athletes was discussed by the participants. More specifically, participant 6 acknowledged that sometimes parents did not offer as much support as required mainly because they perceived sport differently. In line with this, previous research suggests that athletes who had successful transitions had a high amount of appropriate parental involvement (Wuerth et al. 2004). It was also pointed out that when parents are shouting from the sidelines while athletes are competing, it can create unnecessary pressure, particularly taking into account the fact that young athletes are less likely to know how to cope with spectators and external pressure at a young age. Relevant research has shown that parents who demand transient results may create a fear of failure to their children. On the contrary, children with autonomy supportive parents are more likely to develop a stronger sense of personal control (Gagne 2003).

'My parents did not support me enough; they thought it was something secondary, just a hobby, just exercise and nothing else. But for me, it was not just exercise it meant much more to me.'

Participant 6

'Many players had their parents around them all the time shouting and I don't think this helped them. I was more anxious when my parents were around because at that age a kid doesn't know how to deal with this external pressure'.

Participant 1

\section{Challenges of Combining Sport with Studies}

Time constraints and physical exhaustion were the main obstacles for athletes who attempted to combine a career in sport along with their studies and/or work. 
Spending too many hours training (participant 3) made it challenging for him to study for school after training. Participant 2 continued participating throughout her final year of high school and as a university student stated that it was exhausting for her to cope with training and lectures at the university. This period of pressure and overlapping transitions that collides with the transition period from junior to senior level in sport has been described as very challenging (Wylleman and Lavallee 2004). Combining studies with a sport career is a common challenge in research examining within-career transitions (Fin \& McKenna, 2010) and excessive pressure has also been linked with dropout (Salguero et al. 2003).

'Combining sport with school was very hard because we spent around 6 hours at training, 2 and a half hours in the water then after half an hour we had to go the gym for 2 and a half hours so it was quite challenging to go back home after this and study for school.'

Participant 3

If you have double training and gym 3 times per week and the rest of the days just training automatically you can't attend some of the classes at the university, you can't work or even if you do work you can't work full time. I liked my course so I started going more regularly to the university and continued training 10 times per week. And I was knackered...'

Participant 2

Furthermore, athletes missed many classes because their competitions especially those participating in swimming are organised in 3-4 day tournaments. Consequently, they had gaps in certain classes and found it hard to follow up since their schools did not offer them support. Surprisingly, in one case (participant 4) despite the fact she attended a sport school no support was offered to her and she had to seek help from the Ministry of Education. Interestingly, recent studies have shown that components of life (i.e., psychosocial, academic, vocational) may act as a support to athletes, especially during challenging periods in the athletic career. (Debois, 2015)

'Being 12, 13, 14 and live far from your family and not going to school is tough. I was a good student and the principal of the school wanted me and another girl to fail because we had lost too many classes throughout the year. Therefore, we had to go the minister of education to get a specific permission to give exams because we were absent too many times. Imagine what I did; how much I wanted it. Take into account I was in a sport school as well.'

Participant 4

External pressure from teachers, parents and the society in general regarding the results of the national exams and the future choices for their career was a psychological load during that time. Athletes felt that everything depended on their results for the national exams, which is something they did not like. Additionally, the existing culture in Greece, dictates that youngsters should focus on their studying and their life goals in the long term instead of chasing a career in sport. This is because the results of the national exams will determine the university they 
will enter so as their future professional career (at least according to the social norms). No opportunities are given to student-athletes to combine a dual career so it is up to them to take the decision to try to do both or choose in which they focus most of their efforts. Notably, the Ministry of Education in Greece has recently (2017) suggested changing the current approach in order create a more holistic educational system which will not be based solely on the results of the national exams. In addition, the EU guidelines on Dual Career of Athletes (2012), which were designed to "create the right environment for dual careers of athletes, including an appropriate legal and financial framework" were recently translated in Greek. As such, programmes like the Career Assistance Program, which was designed to help athletes to cope with a dual career in Spain (López et al. 2015) would usefully be implemented in Greece as well.

'During high school [Lyceum] I was pressured psychologically to decide what I want to do. I didn't have much time for training, I had private classes to get prepared for school and generally, Ifelt pressure about what to do with my life...'

Participant 6

'You have to go and study and it is sensible to continue your development as a person. From the one side, you identify your options and if it is worthwhile staying in your city and from the other hand you need to take into account that swimming and sport, in general, are good for now but will they be for the long-term? So you have to make a choice at that time.'

Participant 1

An example was given of how coaches may influence the dual career of athletes by not taking into account the student identity of the athletes by undermining the importance of exams or other commitments. Therefore, it is important that all the influential parties actively support student-athletes to effectively balance their academic and athletic career.

I remember a teammate that competed at the Olympics who argued with her coach because she had exams for the university and wanted to complete her studies since she was in her final year studying in the medical school. However, her coach registered her for an international competition.'

Participant 2

\section{General Discussion}

The current study attempted to investigate the development experiences and transition experiences of talented athletes who had an unsuccessful transition from junior to senior level and to identify factors (environmental and individual) that contribute to unsuccessful transitions. Athletes in the current study did not attribute their unsuccessful transition from junior to senior level only to one reason rather than to a combination of different factors. A variety of factors were shown to be influential for career progression in this study. More specifically, early success and win-focus environments, negative impact of coaches and different stakeholders, 
lack of communication and support towards athlete wellbeing, and the challenges of combining studies with sport were shown to contribute to an unsuccessful transition from junior to senior level in sport.

The originality and significance of this work is due to the lack of research with this important population and the uniqueness of the sample. More specifically the sample was unique because a) all the participants were talented athletes competing at elite youth/adult level before dropping out during the transition from junior to senior level, b) all the participants were Greek athletes developing during the economic crisis in the country. Those two reasons make the sample particularly unique as the majority of the studies examining drop out have recruited adolescence athletes (Crane and Temple 2015). In addition, only a limited number of studies have investigated dropout during junior to senior level but not necessarily at elite level nor in a Greek context. It would be beneficial for future studies to consider adopting a longitudinal approach to track down the progress of the participants; focus on only one sport; investigate different cultures or 'match' the participants which would allow comparisons between successful and less or unsuccessful peers. This methodology was recently employed by Collins et al. (2016) to examine the differences in the development pathways of 'super champions', 'champions' and 'almosts'.

The findings of the current study presented a broad picture of the experiences of athletes who were unsuccessful in the transition from junior to senior level in Greece highlighting the challenges that are likely to occur during that particular transition. On the other hand, it should be taken into account that each sport has different needs, athletes may face different challenges and their response may vary depending on their gender and their previous experiences. To facilitate effective development coaches, clubs and policy makers need to focus more on understanding the athletes, creating a task-oriented environment and focusing on long-term goals and provision for late developers. Those principles have been discussed in the literature focusing on effective talent development in various sports and cultures (English et al. 2018, Henriksen et al. 2010a, 2010b, Martindale et al. 2007). Those principles coupled with the right balance between challenge and support in terms of competition and balancing a dual career would facilitate the development of talented athletes. Considering the fact that it is practically impossible for all youth talented athletes to 'make it' to elite level, the priority should be to create positive environments for youth athletes to fail in a healthy way. This will enable them to develop holistically and acquire a multitude of psychosocial skills that can be used in various domains of their lives in the future.

\section{References}

Alfermann D (1995) Career transitions of elite athletes: drop-out and retirement. In R Vanfraechem-Raway, Y Vanden Auweele (eds) Proceedings of the Ninth European Congress of Sport Psychology, 828-833. Brussels: European Federation of Sports Psychology FEPSAC. 
Amorose AJ, Anderson-Butcher D (2007) Autonomy-supportive coaching and selfdetermined motivation in high school and college athletes: A test of selfdetermination theory. Psychology of Sport and Exercise 8(5): 654-670.

Andronikos G, Elumaro AI, Westbury T, Martindale RJ (2016) Relative age effect: implications for effective practice. Journal of Sports Sciences 34(12): 1124-1131.

Backstrom CH, Hursch-Ceasar G (1981) Conducting Interviews: Survey Research, $2^{\text {nd }}$ ed. New York: John Wiley and Sons.

Balish SM, McLaren C, Rainham D, Blanchard C (2014) Correlates of youth sport attrition: A review and future directions. Psychology of Sport and Exercise 15(4): 429-439.

Baron-Thiene A, Alfermann D (2015) Personal characteristics as predictors for dual career dropout versus continuation-A prospective study of adolescent athletes from German elite sport schools. Psychology of Sport and Exercise 21: 42-49.

Barreiros A, Côté J, Fonseca AM (2014) From early to adult sport success: Analysing athletes' progression in national squads. European Journal of Sport Science 14(1): 178-182.

Bass B M, Avolio BJ, Jung DI, Berson Y (2003) Predicting unit performance by assessing transformational and transactional leadership. Journal of Applied Psychology 88(2): 207.

Bloom BS (1985) Developing Talent in Young People. New York: Ballantine.

Bono JE, Foldes HJ, Vinson G, Muros JP (2007) Workplace emotions: The role of supervision and leadership. Journal of Applied Psychology 92(5): 1357-1367.

Braun V, Clarke V (2006) Using thematic analysis in psychology. Qualitative Research in Psychology 3(2): 77-101.

Brazo-Sayavera J, Martínez-Valencia MA, Müller L, Andronikos G, Martindale RJ (2017) Identifying talented track and field athletes: The impact of relative age effect on selection to the Spanish National Athletics Federation training camps. Journal of Sports Sciences 35(22): 2172-2178.

Brouwers J, De Bosscher V, Sotiriadou P (2012) An examination of the importance of performances in youth and junior competition as an indicator of later success in tennis. Sport Management Review 15: 461-475.

Bruner MW, Munroe-Chandler KJ, Spink KS (2008) Entry into elite sport: A preliminary investigation into the transition experiences of rookie athletes. Journal of Applied Sport Psychology 20(2): 236-252.

Burgess DJ, Naughton GA (2010) Talent development in adolescent team sports: A review. International Journal of Sports Physiology and Performance 5: 103-116

Burke LA, Miller MK (2001) Phone interviewing as a means of data collection: Lessons learned and practical recommendations. In Forum Qualitative Sozialforschung/ Forum: Qualitative Social Research 2(2): Art 7.

Butcher J, Lindner KJ, Johns DP (2002) Withdrawal from competitive youth sport: A retrospective ten-year study. Journal of Sport Behavior 25(2): 145.

Butt J, Molnar G (2009) Involuntary career termination in sport: A case study of the process of structurally induced failure. Sport in Society 12(2): 240-257.

Collins D, MacNamara Á (2012) The Rocky Road to the Top Why Talent Needs Trauma. Sports Medicine 42(11): 907-914.

Collins D, MacNamara Á, McCarthy N (2016) Super champions, champions, and almosts: important differences and commonalities on the rocky road. Frontiers in Psychology 6: 2009.

Côté J, Baker J, Abernethy B (2007) Practice and play in the development of sport expertise. Handbook of Sport Psychology 3: 184-202. 
Côté J, Lidor R, Hackfort D (2009) ISSP position stand: To sample or to specialize? Seven postulates about youth sport activities that lead to continued participation and elite performance. International Journal of Sport and Exercise Psychology 7(1): 7-17.

Crane J, Temple V (2015) A systematic review of dropout from organized sport among children and youth. European Physical Education Review 21(1): 114-131.

Creswell, J. (1984). Research Design: Qualitative and Quantitative Approaches. Thousand Oaks, CA: Sage, 1994.

Debois N, Ledon A, Wylleman P (2015) A lifespan perspective on the dual career of elite male athletes. Psychology of Sport and Exercise 21: 15-26.

Deci EL, Ryan RM (2000) The" what" and" why" of goal pursuits: Human needs and the self-determination of behavior. Psychological Inquiry 11(4): 227-268.

Deci EL, Ryan RM (2008) Self-determination theory: A macrotheory of human motivation, development, and health. Canadian Psychology/Psychologie Canadienne 49(3): 182.

Edwards T, Kingston K, Hardy L, Gould D (2002) A qualitative analysis of catastrophic performances and the associated thoughts, feelings, and emotions. The Sport Psychologist 16(1): 1-19.

English C, Nash C, Martindale R (2018) The effects of structural change: an investigation into the South African cricket development pathway. International Journal of Sport Policy and Politics 10(2) 371-391.

Finn J, McKenna J (2010) Coping with academy-to-first-team transitions in elite English male team sports: the coaches' perspective. International Journal of Sports Science \& Coaching 5(2): 257-279.

Fraser-Thomas J, Côté J, Deakin J (2008) Understanding dropout and prolonged engagement in adolescent competitive sport. Psychology of Sport and Exercise 9(5): 645-662.

Gagné F (2004) Transforming gifts into talents: The DMGT as a developmental theory. High Ability Studies 15(2): 119-147.

Gagne M (2003) Autonomy support and need satisfaction in the motivation and wellbeing of gymnasts. Journal of Applied Sport Psychology 15(4): 372-390.

Giannoulakis C, Papadimitriou D, Alexandris K, Brgoch S (2017) Impact of austerity measures on National Sport Federations: evidence from Greece. European Sport Management Quarterly 17(1) 75-97.

Gledhill A, Harwood C (2015) A holistic perspective on career development in UK female soccer players: A negative case analysis. Psychology of Sport and Exercise 21: 65-77.

Gledhill A, Harwood C, Forsdyke D (2017) Psychosocial factors associated with talent development in football: A systematic review. Psychology of Sport and Exercise 31: 93-112.

Graneheim UH, Lundman B (2004) Qualitative content analysis in nursing research: concepts, procedures and measures to achieve trustworthiness. Nurse Education Today 24(2): 105-112.

Guest G, Namey EE, Mitchell ML (2013) Defining and Designing. In Collecting Qualitative Data: A Field Manual for Applied Research, 1-40. SAGE Publications, Inc.

Hardon A, Hodgkin C, Fresle DA (2004) How to Investigate the Use of Medicines by Consumers. World Health Organisation.

Hecimovich M (2004) Sport specialization in youth: A literature review. Journal of the American Chiropractic Association 41(4): 32-41.

Henriksen K, Larsen CH, Christensen MK (2014) Looking at success from its opposite pole: The case of a talent development golf environment in Denmark. International Journal of Sport and Exercise Psychology 12(2): 134-149. 
Henriksen K, Stambulova N, Roessler KK (2010a) Successful talent development in track and field: considering the role of environment. Scandinavian Journal of Medicine \& Science in Sports 20: 122-132.

Henriksen K, Stambulova N, Roessler KK (2010b) Holistic approach to athletic talent development environments: A successful sailing milieu. Psychology of Sport and Exercise 11(3): 212-222.

Hetland H, Sandal GM, Johnsen TB (2007) Burnout in the information technology sector: Does leadership matter?. European Journal of Work and Organizational Psychology 16(1): 58-75.

Holt NL, Mitchell T (2006) Talent development in English professional soccer. International Journal of Sport Psychology 37(2/3): 77.

Kirk D (2005) Physical education, youth sport and lifelong participation: the importance of early learning experiences. European Physical Education Review 11(3): 239-255.

Koukouris K (1991) Quantitative aspects of the disengagement process of advanced and elite Greek male athletes from organized competitive sport. Journal of Sport Behavior 14(4): 227.

Koukouris K (2001) Disengagement of elite gymnastics from organized competitive gymnastics. In 10th World Congress of Sport Psychology, Skiathos, Hellas.

Koukouris K (2005) Premature athletic disengagement of elite Greek gymnasts. European Journal for Sport and Society 2(1): 35-56.

Lauer L, Gould D, Roman N, Pierce M (2010) Parental behaviors that affect junior tennis player development. Psychology of Sport and Exercise 11(6): 487-496.

Lincoln YS, Guba EG (1989) Ethics: The failure of positivist science. The Review of Higher Education 12(3): 221-240.

López C, Barriopedro M, Conde E, Sánchez J, Ubago E, Gallardo L (2015) Analysis of the barriers perceived by Spanish elite athletes to access the studies. Cuadernos de Psicología del Deporte 15(1): 265-274.

MacNamara Á, Button A, Collins D (2010a) The Role of Psychological Characteristics in Facilitating the Pathway to Elite Performance Part 1: Identifying Mental Skills and Behaviors. The Sport Psychologist 24: 52-73.

MacNamara Á, Button A, Collins D (2010b) The Role of Psychological Characteristics in Facilitating the Pathway to Elite Performance Part 2: Examining Environmental and Stage-Related Differences in Skills and Behaviors. The Sport Psychologist 24: 74-96.

Maennig W (2005) Corruption in international sports and sport management: Forms, tendencies, extent and countermeasures. European Sport Management Quartely 5(2): $187-225$.

Martindale RJ, Collins D, Abraham A (2007) Effective talent development: The elite coach perspective in UK sport. Journal of applied sport psychology 19(2): 187-206.

Meyer JP, Becker TE, Vandenberghe C (2004) Employee commitment and motivation: a conceptual analysis and integrative model. Journal of Applied Psychology 89(6): 991.

Mills A, Butt J, Maynard I, Harwood C (2012) Identifying factors perceived to influence the development of elite youth football academy players. Journal of Sports Sciences 30(15): 1593-1604.

Morris R, Tod D, Eubank M (2016) From youth team to first team: An investigation into the transition experiences of young professional athletes in soccer. International Journal of Sport and Exercise Psychology 1-17.

Morris R, Tod D, Oliver E (2015) An analysis of organizational structure and transition outcomes in the youth-to-senior professional soccer transition. Journal of Applied Sport Psychology 27(2): 216-234. 
Nielsen K, Munir F (2009) How do transformational leaders influence followers' affective well-being? Exploring the mediating role of self-efficacy. Work \& Stress 23(4): 313329.

Nielsen K, Randall R, Yarker J, Brenner SO (2008) The effects of transformational leadership on followers' perceived work characteristics and psychological wellbeing: A longitudinal study. Work \& Stress 22(1): 16-32.

Park S, Lavallee D, Tod D (2013) Athletes' career transition out of sport: A systematic review. International Review of Sport and Exercise Psychology 6(1): 22-53.

Patton M (1990) Qualitative Evaluation Methods, $2^{\text {nd }}$ ed. Beverly Hills, CA: Sage.

Patton MQ (2002) Two decades of developments in qualitative inquiry: A personal, experiential perspective. Qualitative Social Work 1(3): 261-283.

Piereson S (1983) In Search of Excellence: Lessons from America's Best-Run Companies. By Thomas J. Peters and Robert H. Waterman, Jr. New York: Harper \& Row, 1982. NASSP Bulletin 67(466): 120-121.

Richardson D, Littlewood M, Nesti M, Benstead L (2012) An examination of the migratory transition of elite young European soccer players to the English Premier League. Journal of Sports Sciences 30(15): 1605-1618.

Ryba TV, Stambulova NB, Si G, Schinke RJ (2013) ISSP position stand: Culturally competent research and practice in sport and exercise psychology. International Journal of Sport and Exercise Psychology 11(2): 123-142.

Rynne SB, Mallett CJ, Tinning R (2010) Workplace learning of high performance sports coaches. Sport, Education and Society 15(3): 315-330.

Salguero A, Gonzalez-Boto R, Tuero C, Marquez S (2003) Identification of dropout reasons in young competitive swimmers. Journal of Sports Medicine and Physical Fitness 43(4): 530.

Schinke RJ, McGannon KR, Smith B (2013) Expanding the sport and physical activity research landscape through community scholarship: Introduction. Qualitative Research in Sport, Exercise and Health 5: 287-290.

Shenton AK (2004) Strategies for ensuring trustworthiness in qualitative research projects. Education for Information 22(2): 63-75.

Sheridan D, Coffee P, Lavallee D (2014) A systematic review of social support in youth sport. International Review of Sport and Exercise Psychology 7(1): 198-228.

Simonton DK (1999) Talent and its development: An emergenic and epigenetic model. Psychological Review 106(3): 435.

Stambulova N (2003) Symptoms of a crisis-transition: A grounded theory study. In N Hassmén (ed) SIPF Yearbook 2003, 97-109. Örebro: Örebro University Press.

Stambulova NB (1994) Developmental sports career investigations in Russia: A postperestroika analysis. The Sport Psychologist 8(3): 221-237.

Stambulova NB (2017) Crisis-transitions in athletes: current emphases on cognitive and contextual factors. Current Opinion in Psychology 16: 62-66.

Stambulova N, Alfermann D, Statler T, Côté J (2009) ISSP position stand: Career development and transitions of athletes. International Journal of sport and Exercise Psychology 7(4): 395-412.

Terry G, Hayfield N, Clarke V, Braun V (2017) Thematic analysis. The Sage handbook of Qualitative Research in Psychology 17-37.

Wall M, Côté J (2007) Developmental activities that lead to dropout and investment in sport. Physical Education and Sport Pedagogy 12(1): 77-87.

Wuerth S, Lee MJ, Alfermann D (2004) Parental involvement and athletes' career in youth sport. Psychology of Sport and Exercise 5(1) 21-33. 
Wylleman P, Lavallee D (2004) A developmental perspective on transitions faced by athletes. In M Weiss (ed) Developmental sport and exercise psychology: A lifespan perspective, 507-527. Morgantown, WV: Fitness Information Technology. 